\title{
The Effect of Age on Cognitive Performance Under the Impact of Vibration in a Driving Environment
}

\author{
Mohammad Muzammil \\ Z.H. College of Engineering \& Technology, A.M. University, Aligarh, U.P., India
}

The effect of organismic variable age on human cognitive performance was studied under the impact of vibration in different automobile driving environments, namely city streets, rural roads and highways. Reaction time was measured in milliseconds through a human response measurement system specifically designed for the purpose. Results of the study showed that age had a significant effect in city street and rural road conditions. It was also found that the level of equivalent acceleration of vibration and a difficulty index significantly affected cognitive performance in all driving conditions. The organismic variable age observed to have a significant effect on task performance implied that youngsters and older people are stressed differently in specific environments of driving so proper stress management strategies should be evolved for them in order to minimize the number of accidents.

equivalent acceleration of vibration difficulty index driving environment cognitive performance reaction time

\section{INTRODUCTION}

There has been an explosive growth in the use of vehicles all over the world in the late 20th century. People belonging to almost all walks of life either own the vehicles or very frequently use a leased one. The frequent use of vehicles has led to questions as to whether drivers are subjected to environmental stressors within acceptable limits or not. The human-vehicle system environment is one in which continuous manual control or frequent tracking needs to be exercised. Human performance is directly dependent on the physical and mental capabilities and limitations of the concerned operator and as every transportation system induces vibration, cognitive performance is affected in its presence. Low-frequency vibrations can be extremely severe depending upon the terrain and speed of travel [1]. Carrying out a task under normal circumstances and within a narrow range of vibration induced stresses would take up a certain amount of mental capacity. Carrying out difficult tasks would tax mental capacity until a point when spare mental capacity would get exhausted and thus performance decrements would appear to be quite pronounced. Shoenberger [2] demonstrated that reduction in cognitive performance took place due to difficulties in perceiving the stimulus in the presence of vibration. As people's average life expectancy rate is increasing with the advancement of medical technology, and since a large number of aged population is driving vehicles, there is a need to design a system compatible with their capacities and limitations. Previous research $[3,4]$ has shown that information processing capabilities were dependent on age. Yamamoto et al. [5], while studying the ability of a worker to perform a task, observed the significant effect of age. Other researchers [6, 7] have also found that in divided-attention kinds of tasks, the task involved was significantly affected by age differences. Literature reviewed on the theme of

Correspondence and requests for offprints should be sent to Mohammad Muzammil, Mechanical Engineering Department, Z.H. College of Engineering \& Technology, A.M. University, Aligarh, U.P., India. E-mail: <mmuzammil18@yahoo.co.in>. 
vibration showed that either no or very few studies have been conducted in the past on the topic of ageing in the context of vibration exposure during driving. Keeping this in mind the present set of studies was designed to investigate if age was a significant factor in driving. The interaction of age with different levels of difficulty encountered while performing the task was also investigated. Another objective of this study was to examine whether or not vehicular vibration was a significant factor in human driving performance. In view of those objectives, the following null hypotheses were expressed.

1. Adults and old persons do not differ in their performance under the impact of vehicular vibration when driving on a city street, rural road or highway.

2. Varying levels of equivalent acceleration of vibration do not have different effects on human performance in the kind of task considered.

3. Varying levels of difficulty in a cognitive task require the same amount of reaction time when driving in the three environments considered.

\section{METHOD}

\subsection{Subjects}

Twenty-eight male subjects at four age levels (20-30, 30-40, 40-50 and 50-60) with 7 subjects in each category were selected to carry out the experimental investigations. All the subjects had normal vision with no history of neuromuscular disorder.

\subsection{Experimental Setup}

Experimental investigations were conducted in a real life driving environment in a passenger car (Maruti-800). The setup comprising the following sub-systems has been shown through a schematic diagram (Figure 1):

1. A human response measurement system,

2. Circuit 1 and Circuit 2 with bulbs of different colours mounted on them in a proper sequence,

3. A vibration level meter (VR5100, ONO SOKKI Co. Ltd., Japan).

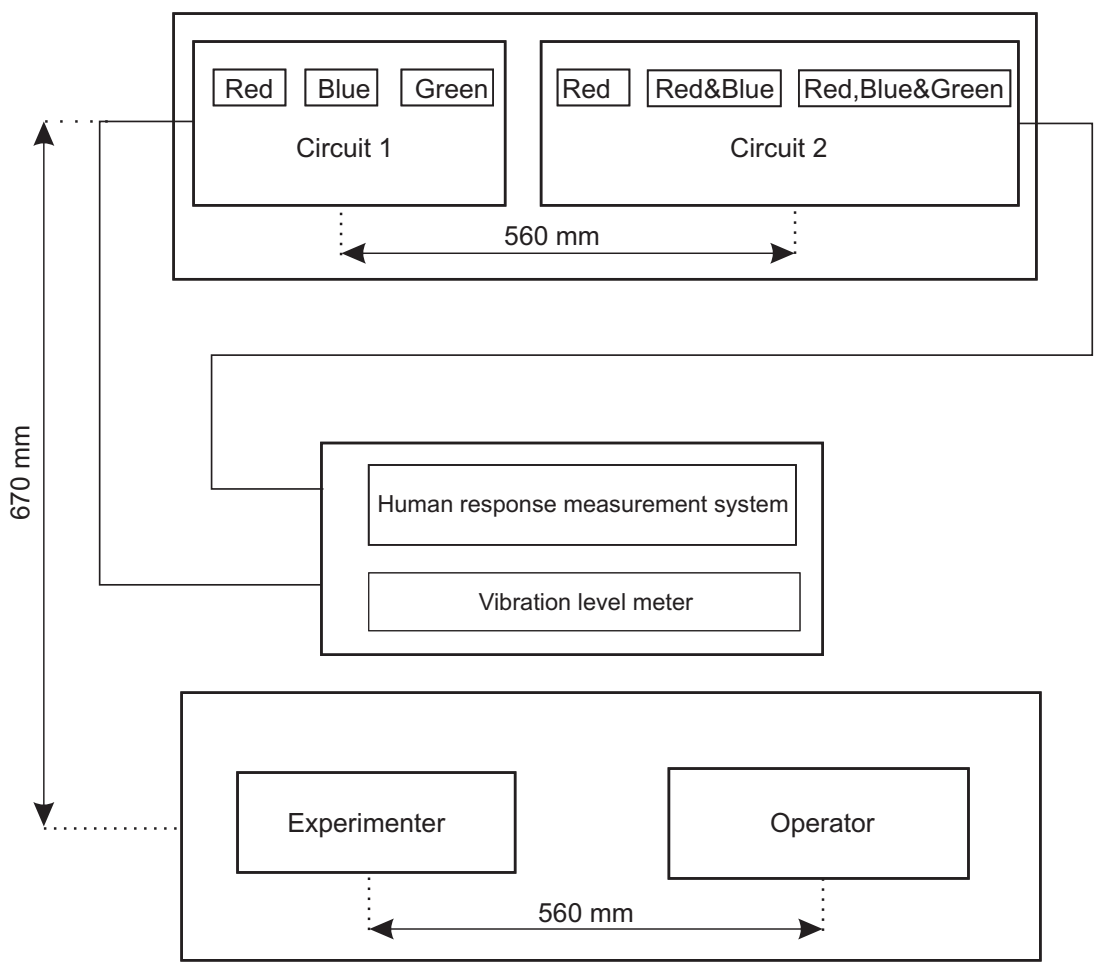

Figure 1. A schematic diagram of the experimental setup. 


\subsection{General Experimental Procedure}

The following preparatory steps were undertaken before the actual experiment was conducted.

1. Each subject was briefed about the objective of the experiment.

2. Instructions to be followed while performing the experimental task were given to the subjects.

3. Training sessions were organized for each subject in order to get them familiarized with how to perform the task.

After a subject had taken his seat in the test vehicle and all the instructions had been given, the following steps were taken, in that order, for both the training and experimental sessions.

a. A START signal was given to the subject.

b. A stimulus was presented to the subject by the experimenter in the form of lighting different coloured bulbs provided on a wooden board.

c. The subject responded by switching on the same coloured bulb provided on another board.

d. The reaction time was noted by the experimenter.

The experiment was conducted in three independent driving environments undertaken in the study for every level of difficulty under varying equivalent levels of vibration acceleration. While performing the experimental task the level of vibration acceleration in the different driving environments was kept at a pre-determined value by constantly monitoring the level in the $x, y$ and $z$ directions manipulating the speed of the vehicle. In every cycle of the operation, a rest period of $30 \mathrm{~min}$ was provided for the subjects. Human performance in terms of response time was recorded at approximately the same time of the day on each day of the experiment. This was so in order to eliminate any temporal effect in the experiment that might have its impact on the subject's performance.

\subsection{Driving Environment}

The present study was conducted in three independent driving environments, namely city streets, rural roads and highways. The components of traffic are different in different driving environments. For example, on city roads there are minibuses, cars, auto rickshaws, twowheelers, etc., while on rural roads there are agricultural tractors, manually driven rickshaws, bicycles, tongas. As far as traffic on highways is concerned, it generally comprises buses, trucks, cars and heavy vehicles. Traffic density and the nature of traffic greatly influence driving performance. The brain receiving a stimulus sends signals to various biological resources to cope with the situation and act according to the demand of the driving task. The width of the roads, too, has an important influence on the mental condition of the operator.

\subsection{Difficulty Index}

Three levels of a difficulty index were distinguished in the present research. Difficulty index level 1 comprised of one red bulb (a simple reaction time task). Difficulty index level 2 had two bulbs, red and blue (reaction time with two alternatives) while three bulbs (red, blue and green) were used for difficulty index level 3 , this being the case of a reaction time task with three alternatives.

\subsection{Vibration Levels}

A study was carried out to determine the level of vibration acceleration in the $x, y$ and $z$ directions to which operators were subjected while driving automobiles in different driving environments. Total equivalent acceleration of vibration was calculated as per the recommendations of Standard No. ISO 2631-1:1997 [8]. It was found that total vibration varied from 0.45 to $2.66 \mathrm{~m} / \mathrm{s}^{2}$. In light of this study equivalent acceleration of vibration levels were set at $0,0.94,1.82$ and $2.66 \mathrm{~m} / \mathrm{s}^{2}$ for all the driving environments considered in the present work. 


\subsection{Stimuli and the Experimental Task}

Stimuli were presented to the subjects in the form of a difficulty index to determine reaction time. The stimuli remained fixed throughout the experimental sessions. Stimuli were presented at three levels so as to determine simple reaction time and choice reaction time. The subjects were asked to operate the switch for the same type (colour) of bulb which was turned on by the experimenter. For this purpose, two wooden boards were used. The board operated by the experimenter had three positions of the bulb. At location 1 , only one bulb was used, at location 2 , two bulbs (red and blue) were turned on and at location 3, three bulbs (red, blue and green) were used for measuring reaction time.

Throughout the experiment, the subject sat on a seat in a normal sitting position and was asked to switch on at location 1 after the bulb of the same colour was lit on the experimenter's board. The subject was also told to maintain a normal sitting posture throughout the experiment. The subject had prior information that a red bulb would be illuminated (difficulty index level 1). The same procedure was used in the second setting with the difference that either of the two bulbs on the experimenter's board could be lit and on seeing the colour of the lit bulb, the subject had to switch on the bulb of the same colour at location 2 (difficulty index level 2). Similarly for the third setting, the experimenter switched on any of the three bulbs on the board and the subject responded by switching on the same coloured bulb at location 3 (difficulty index level 3). The experiments for all the three settings were performed at a pre-specified level of vibration and in pre-specified driving condition (city street, rural road or highway). Reaction time was measured, in milliseconds, with an electronic system designed and developed for the purpose.

\subsection{Design and Development of a Human Response Measurement System}

A robust and accurate system was required for measurements in the type of task undertaken in this research as the time required for measuring the response was of the order of milliseconds. Keeping this requirement in view, a system was designed such that it started at the start of the stimulus and ended as the response to this stimulus was executed. The system was made to operate in the range of 1-9,999 milliseconds. The electronic components/chips used and their function in fabrication of the human response measurement system are described here.

A 7404 hexadecimal inverter was used to construct a TTL (Transistor-Transistor Logic)compatible clock. The 7404 IC consists of six inverters hence the name hexadecimal inverter. After applying $+5 \mathrm{~V}$ (the supply voltage of all TTL devices) to pin 14 and ground pin 7, any one or all the inverters can be connected to other TTL devices. A 1-MHz crystal oscillator through two resistances $(1 \mathrm{~K} \Omega$ each) and a capacitor $(1 \mu \mathrm{F})$ were connected to generate a clock. This clock was passed through decade counters (IC 74160) connected in series. A decade counter is employed for dividing a pulse frequency exactly by 10 . The $1-\mathrm{KHz}$ output obtained after the third stage was supplied to IC 7411 which was a triple three input AND gate. In an AND gate when all inputs are low, all diodes conduct therefore output is low. If even one point is low, output is in the low state because the diode connected to the low input remains on. The only way to get high output is to bring all inputs to the high state $(+5 \mathrm{~V})$. Then all diodes stop conducting and the supply voltage $(+5 \mathrm{~V})$ pulls the output up to the high state. The output of the four-decade counters (for thousands, hundreds, tens and ones) is BCD input for decoder/driver (IC 7448). BCD is an abbreviation for Binary Coded Decimal. The BCD code expresses each digit in a decimal number by its nibble equivalent. The internal logic of IC 7448 (decoder/driver) converts the BCD input to the required output. The output of the IC 7448 was supplied to the seven segment indicator, i.e., seven LEDs. By forward biasing different LEDs, the digits from 0 to 9 can be displayed. A reset switch was also connected in the timer circuit to reset the display at 0 position. 
The 5-V DC supply was given to the TTL circuit through a $12-\mathrm{V}$ battery.

With this TTL circuit, circuit 1 with three bulbs (red, green and blue) and circuit 2 with three combinations of bulbs (red, red and green, and red, green and blue) were made compatible. Circuit 1 contained four points: point through which resistance $(1 \mathrm{~K} \Omega)$ for the bulb of circuit 1 is connected, ground, switch and a resistance point 1 for the bulbs of circuit 2. Circuit 2 had two points: a switch for operating the bulbs and resistance $(1 \mathrm{~K} \Omega)$ point 2 . Pin number 4 of IC 7404 was connected to resistance point 2 and pin number 2 of IC 7411 was joined with resistance point 1 . The switches of circuit 1 and 2 were connected to a supply from the battery and resistance point 2 was connected to the negative of circuit 2. The supply of 5V DC was obtained from the same battery from which the TTL circuit was energized. When the experimenter operates the switch for a particular bulb the clock starts running and the display shows the time. As soon as the subject responds to this stimulus and lights the bulb of the same colour in the circuit 2 by operating the switch, the clock stops moving. The time spent during this process can be read directly in milliseconds.

\subsection{Statistical Analysis}

A three-factor ANOVA was carried out to determine the effects of parameters under investigation. The independent variables taken were organismic variable age (at four levels, $20-30,30-40,40-50$ and 50-60) vibration (0, $0.94,1.82$ and $2.66 \mathrm{~m} / \mathrm{s}^{2}$ ) and the difficulty index (at three levels) while reaction time (measured in milliseconds) was the dependent variable.

\subsection{Vibration Measurement}

The vibration level meter (VR 5100, ONO SOKKI Co. Ltd. Japan) based on Japanese Industrial Standards (JIS C 1510-1976) and the measurement law of Japan was used to measure the equivalent level of vibration acceleration in each $x, y$ and $z$ direction. The vibration pickup
(NP-7210) with three independent shear type piezoelectric elements for detecting signals was placed on the seat of the car on a specially prepared hard disc as per the recommendations of Standard No. ISO 2631-1:1997 [8]. The vibration acceleration levels were measured with respect to the standard biodynamic coordinate system according to ISO 2631-1:1997. The vibration level meter was calibrated in the $x, y$ and $z$ directions prior to measurements. The measuring level range of the equipment and the measuring frequency range were 30 to $120 \mathrm{~dB}$ and 1 to $90 \mathrm{~Hz}$ respectively. To check the suitability of the basic evaluation method, the crest factor was calculated for the $x, y$ and $z$ directions. According to ISO 2631-1:1997, the crest factor is defined as the modulus of the ratio of the maximum instantaneous peak value of the frequency weighted acceleration signal to its rms value. The peak shall be determined over the duration of measurement. The crest factor values obtained for the $x, y$ and $z$ directions were within the limit prescribed by ISO 2631-1:1997. As per ISO 2631-1:1997 recommendations, for vibration with crest factors below or equal to 9 , the basic evaluation method is normally sufficient.

\section{RESULTS}

To investigate the effect of age on cognitive performance under the impact of vibration, three experiments were conducted, the details of which are described in sections 3.1., 3.2. and 3.3.

\subsection{Experiment 1}

In this study, cognitive performance under the impact of the ageing of operators in different age groups was investigated at varying levels of difficulty in a city street type driving environment. The results of the ANOVA carried out on the data collected showed that (Table 1) the main effect of the organismic variable age was statistically significant, which indicated that in a cognitive task the human response was dependent upon the age of the operator. The level 
of equivalent acceleration of vibration, the difficulty index, the interaction of age and level of equivalent acceleration of vibration and second order interaction viz. age $\times$ level of vibration $\times$ difficulty index all emerged to be statistically significant. However, the interaction of age and the difficulty index, and vibration acceleration level and the difficulty index were found to be statistically non-significant. The second order interaction thus found significant, necessitated an analysis of the simple main effect for the first order interactions.
The analysis of simple main effects when subjects of varying age performed a task under different levels of equivalent acceleration of vibration (Table 2) indicated that age was statistically significant at all the four levels of equivalent vibration acceleration. The levels of vibration acceleration for age level 1 and 2 (20-30 and 30-40) were also found to be statistically significant. However, for age level 3 and 4 (40-50 and 50-60) the level of vibration acceleration was found to be statistically non-significant. The analysis of simple main effects when subjects of varying age performed the task at three levels of

TABLE 1. ANOVA Results When Operators Performed a Cognitive Task in a City Street Driving Environment

\begin{tabular}{lcccc}
\hline Source of Variation & $\boldsymbol{d f}$ & $\boldsymbol{M S}$ & $\boldsymbol{F}$ & $\boldsymbol{p}$ \\
\hline Between subjects & 27 & 967283.95 & & .00 \\
A (Age) & 3 & 684097.00 & 29.35 & \\
Subjects within groups (Error 1) & 24 & 23307.30 & & .01 \\
Within subjects & 308 & 14922.26 & & .01 \\
B (Equivalent acceleration of vibration level) & 3 & 33051.00 & 4.90 & 4.55 \\
A $\times$ B & 9 & 30689.70 & & .00 \\
B $\times$ subjects within groups (Error 2) & 72 & 6744.15 & .22 \\
C (Difficulty index) & 2 & 1299924.80 & 295.60 & 1.44 \\
A $\times$ C & 6 & 6339.34 & & .18 \\
C $\times$ subjects within groups (Error 3) & 48 & 4397.50 & & .49 \\
B $\times$ C & 6 & 6973.18 & 2.05 & .01 \\
A $\times$ B $\times$ C & 18 & 9578.73 & & .01 \\
B $\times$ C $\times$ subjects within groups & 144 & 4665.92 & & \\
\hline
\end{tabular}

TABLE 2. Analysis of Simple Main Effects When Subjects of Varying Age Performed a Cognitive Task Under Different Levels of Equivalent Acceleration of Vibration in a City Driving Environment

\begin{tabular}{llccc}
\hline Source of Variation & $\boldsymbol{d f}$ & $\boldsymbol{M S}$ & $\boldsymbol{F}$ & $\boldsymbol{p}$ \\
\hline A (Age level) at & & & & .00 \\
$\mathrm{~B}_{1}$ (Equivalent acceleration of vibration level 1) & 3 & 114215.5 & 18.50 & .00 \\
$\mathrm{~B}_{2}$ (Equivalent acceleration of vibration level 2) & 3 & 401199.2 & 6.50 & .02 \\
$\mathrm{~B}_{3}$ (Equivalent acceleration of vibration level 3) & 3 & 253278.3 & 4.10 & .00 \\
$\mathrm{~B}_{4}$ (Equivalent acceleration of vibration level 4) & 3 & 531870.2 & 8.60 &. \\
$\mathrm{~B}$ (Equivalent acceleration of vibration level) at & & & & .01 \\
$\mathrm{~A}_{1}$ (Age level 1) & 3 & 155257.8 & 4.69 & .03 \\
$\mathrm{~A}_{2}$ (Age level 2) & 3 & 121217.8 & 3.66 & .63 \\
$\mathrm{~A}_{3}$ (Age level 3) & 3 & 19698.0 & 0.59 & .10 \\
$\mathrm{~A}_{4}$ (Age level 4) & 3 & 79187.5 & 2.39 & \\
\hline
\end{tabular}


TABLE 3. Analysis of Simple Main Effects When Subjects of Varying Age Performed a Cognitive Task at Different Levels of Difficulty in a City Street Driving Environment

\begin{tabular}{llccc}
\hline Source of Variation & $\boldsymbol{d f}$ & $\boldsymbol{M S}$ & $\boldsymbol{F}$ & $\boldsymbol{p}$ \\
\hline $\mathrm{A}$ (Age level) at & & & & \\
$\mathrm{C}_{1}$ (Difficulty index level 1) & 3 & 1011328.8 & 12.3 & .00 \\
$\mathrm{C}_{2}$ (Difficulty index level 2) & 3 & 1004779.5 & 12.2 & .00 \\
$\mathrm{C}_{3}$ (Difficulty index level 3) & 3 & 770994.3 & 9.3 & .00 \\
$\mathrm{C}($ Difficulty index) at & & & & \\
$\mathrm{A}_{1}$ (Age level 1) & 2 & 1145157.5 & 46.6 & .00 \\
$\mathrm{~A}_{2}$ (Age level 2) & 2 & 1658104.5 & 67.4 & .00 \\
$\mathrm{~A}_{3}$ (Age level 3) & 2 & 1545474.6 & 62.9 & .00 \\
$\mathrm{~A}_{4}$ (Age level 4) & 2 & 927034.7 & 37.7 & .00 \\
\hline
\end{tabular}

TABLE 4. Analysis of Simple Main Effects When Subjects Performed a Cognitive Task at Varying Levels of Difficulty Under Different Levels of Equivalent Acceleration of Vibration in a City Street Driving Environment

\begin{tabular}{lcccc}
\hline Source of Variation & $\boldsymbol{d f}$ & $\boldsymbol{M S}$ & $\boldsymbol{F}$ & $\boldsymbol{p}$ \\
\hline $\mathrm{B}$ (Equivalent acceleration of vibration level) at & & & & \\
$\mathrm{C}_{1}$ (Difficulty index level 1) & 3 & 2018.66 & 0.04 & .98 \\
$\mathrm{C}_{2}$ (Difficulty index level 2) & 3 & 82157.80 & 1.86 & .17 \\
$\mathrm{C}_{3}$ (Difficulty index level 3) & 3 & 103813.20 & 2.35 & .10 \\
$\mathrm{C}$ (Difficulty index) at & & & & \\
$\mathrm{B}_{1}$ (Equivalent acceleration of vibration level 1) & 2 & 1068167.10 & 43.30 & .00 \\
$\mathrm{~B}_{2}$ (Equivalent acceleration of vibration level 2) & 2 & 1411841.30 & 57.40 & .00 \\
$\mathrm{~B}_{3}$ (Equivalent acceleration of vibration level 3) & 2 & 1034472.70 & 42.10 & .00 \\
$\mathrm{~B}_{4}$ (Equivalent acceleration of vibration level 4) & 2 & 1768896.20 & 72.00 & .00 \\
\hline
\end{tabular}

difficulty (Table 3 ) revealed that age for a simple reaction type of task (difficulty index level 1) and for the choice reaction type of tasks (difficulty index level 2 and 3) was statistically significant. The difficulty index level at all four levels of age was also found to be statistically significant. The results of the main effect analysis, when the task was carried out at three levels of the difficulty index under varying levels of equivalent vibration acceleration, indicated that vehicular vibration was statistically non-significant at all the three levels of difficulty while the difficulty index for all four levels of equivalent acceleration of vibration was found to be statistically significant (Table 4).

The relationship between reaction time and the vibration acceleration level for different levels of difficulty was studied and found to have a linearly varying pattern (Figure 2). The graph between reaction time and vibration level for varying age groups was also found to be linear in nature as shown in Figure 3.

The governing equations for reaction time versus vibration acceleration level for varying difficulty levels were obtained as follows:

$$
\begin{gathered}
R T_{\mathrm{D} 1}=661.49+3.53 \mathrm{~V} \\
R T_{\mathrm{D} 2}=753.53+17.69 \mathrm{~V} \\
R T_{\mathrm{D} 3}=856.01+18.95 \mathrm{~V}
\end{gathered}
$$

where $R T_{\mathrm{D} 1}, R T_{\mathrm{D} 2}$ and $R T_{\mathrm{D} 3}$ represent reaction time at difficulty index level 1,2 and 3 respectively and $V$ is the value of equivalent acceleration of vibration. 
The reaction time models involving vibration levels under different age levels (Figure 3) were as follows.

$$
\begin{aligned}
& R T_{\mathrm{A} 1}=642.35+27.03 V \\
& R T_{\mathrm{A} 2}=686.37+35.24 V
\end{aligned}
$$

$$
\begin{gathered}
R T_{\mathrm{A} 3}=808.58-6.45 \mathrm{~V} \\
R T_{\mathrm{A} 4}=894.06-3.79 \mathrm{~V}
\end{gathered}
$$

where $R T_{\mathrm{A} 1}, R T_{\mathrm{A} 2}, R T_{\mathrm{A} 3}$ and $R T_{\mathrm{A} 4}$ represent age level 1, 2, 3 and 4 respectively and $V$ is the value of equivalent acceleration of vibration.

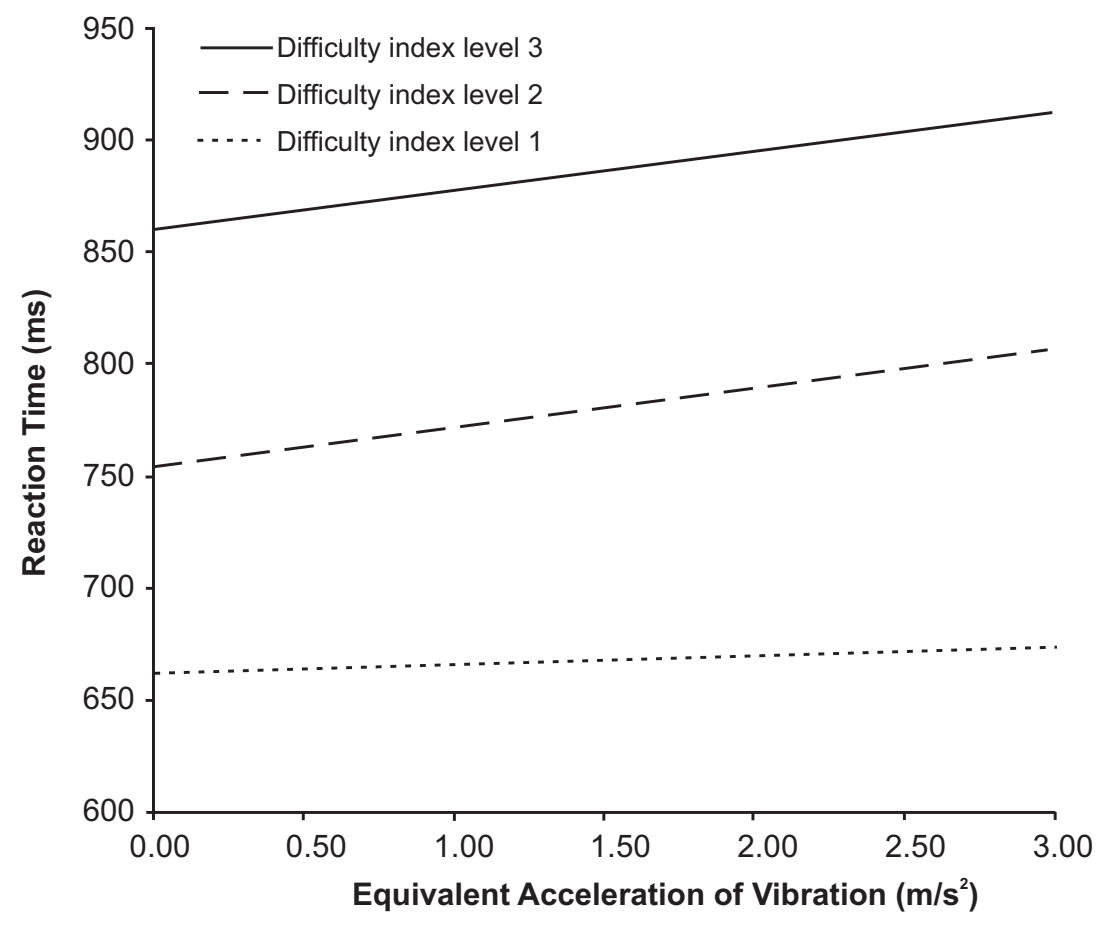

Figure 2. Relationship between reaction time and equivalent acceleration of vibration for different levels of difficulty in a city street driving environment.

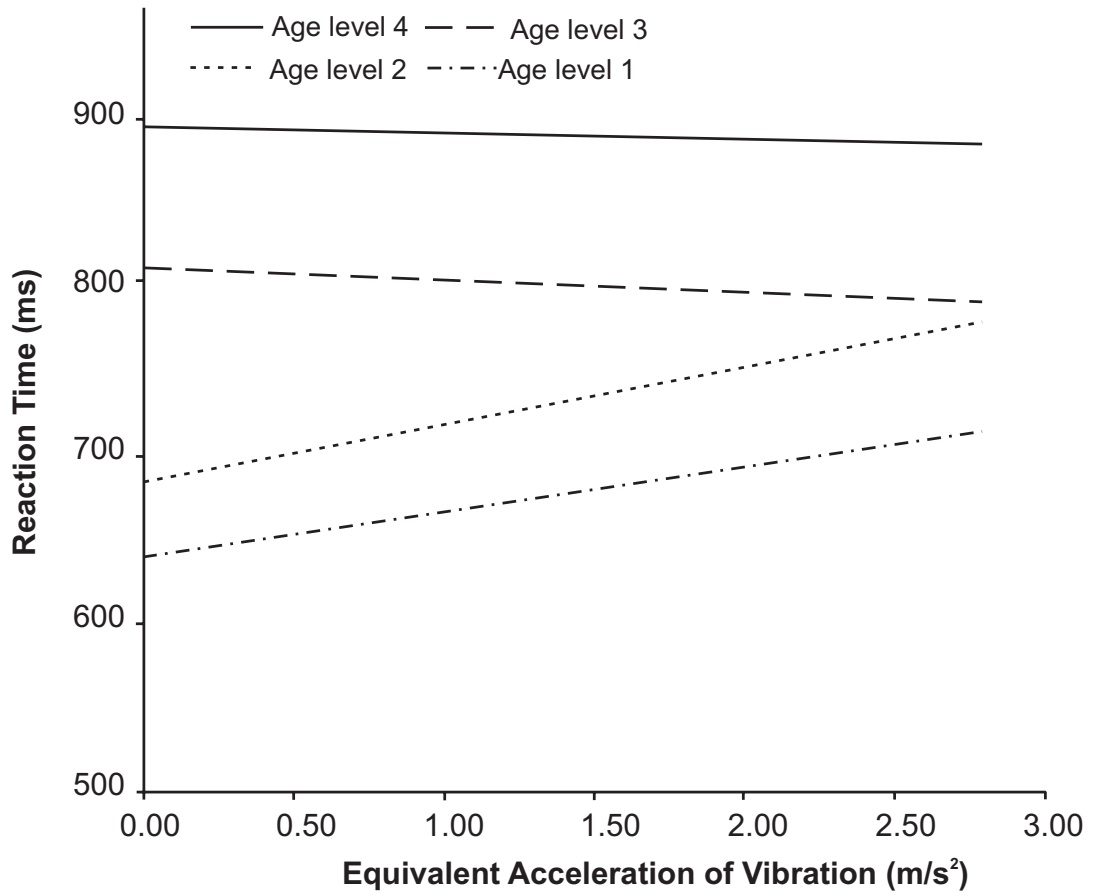

Figure 3. Relationship between reaction time and equivalent acceleration of vibration for varying levels of age in a city street driving environment. 


\subsection{Experiment 2}

In this experiment the investigations were carried out in a rural road driving environment.

Results of the analysis of variance of the data collected presented in Table 5, indicated that the main effects of age, the level of equivalent acceleration of vibration and the difficulty index were statistically significant. The interaction effects of age and equivalent acceleration of vibration level, age and the difficulty index, the level of equivalent acceleration of vibration and the difficulty index and second order interaction age $\times$ level of equivalent acceleration of vibration $\times$ difficulty index all emerged to be statistically significant. The significant second order interaction necessitated an analysis of simple main effects the details of which are presented here.

The results of the analysis of simple main effects (Table 6) showed that age level at all four levels of equivalent acceleration of vibration and equivalent acceleration of vibration at all four levels of age were statistically significant when subjects of varying age performed the cognitive task under varying levels of vehicular vibration. The analysis of simple main effects when subjects of varying age performed the cognitive

TABLE 5. ANOVA Results When Operators Performed a Cognitive Task in a Rural Road Driving Environment

\begin{tabular}{lcccc}
\hline Source of Variation & $\boldsymbol{d f}$ & $\boldsymbol{M S}$ & $\boldsymbol{F}$ & $\boldsymbol{p}$ \\
\hline Between subjects & 27 & 182339.48 & & .00 \\
A (Age) & 3 & 1564909.60 & 164.40 & \\
Subjects within groups (Error 1) & 24 & 9518.22 & & .00 \\
Within subjects & 308 & 15133.09 & & .01 \\
B (Equivalent acceleration of vibration level) & 3 & 308980.93 & 94.28 & 3.12 \\
A $\times$ B & 9 & 10225.04 & & .00 \\
B $\times$ subjects within groups (Error 2) & 72 & 3277.00 & & .01 \\
C (Difficulty index) & 2 & 1439551.10 & 655.85 & 3.08 \\
A $\times$ C & 6 & 6776.23 & & .00 \\
C $\times$ subjects within groups (Error 3) & 48 & 2195.00 & & .20 \\
B $\times$ C & 6 & 7186.26 & 4.20 \\
A $\times$ B $\times$ C & 18 & 5089.94 & 2.97 & .00 \\
B $\times$ C $\times$ subjects within groups & 144 & 1709.92 & & \\
\hline
\end{tabular}

TABLE 6. Analysis of Simple Main Effects When Subjects of Varying Age Performed a Cognitive Task Under Different Levels of Equivalent Acceleration of Vibration in a Rural Road Driving Environment

\begin{tabular}{llccc}
\hline Source of Variation & $\boldsymbol{d f}$ & $\boldsymbol{M S}$ & $\boldsymbol{F}$ & $\boldsymbol{p}$ \\
\hline $\mathrm{A}$ (Age level) at & & & & \\
$\mathrm{B}_{1}$ (Equivalent acceleration of vibration level 1) & 3 & 1645043.0 & 62.6 & .00 \\
$\mathrm{~B}_{2}$ (Equivalent acceleration of vibration level 2) & 3 & 1032899.3 & 39.3 & .00 \\
$\mathrm{~B}_{3}$ (Equivalent acceleration of vibration level 3) & 3 & 1166095.8 & 44.4 & .00 \\
$\mathrm{~B}_{4}$ (Equivalent acceleration of vibration level 4) & 3 & 942716.1 & 35.8 & .00 \\
$\mathrm{~B}$ (Equivalent acceleration of vibration level) at & & & & .00 \\
$\mathrm{~A}_{1}$ (Age level 1) & 3 & 341664.6 & 34.1 & .00 \\
$\mathrm{~A}_{2}$ (Age level 2) & 3 & 376417.6 & 37.6 & .00 \\
$\mathrm{~A}_{3}$ (Age level 3) & 3 & 131343.4 & 13.1 & .00 \\
$\mathrm{~A}_{4}$ (Age level 4) & 3 & 169542.6 & 16.9 & .00 \\
\hline
\end{tabular}


task at varying levels of difficulty (Table 7) found that age was statistically significant. The difficulty index level was also found to be statistically significant at all four levels of age. The analysis of simple main effects also showed that the level of equivalent acceleration of vibration at all three levels of difficulty and the difficulty index at all four levels of equivalent acceleration of vibration were statistically significant when subjects of age level 1 and 2

TABLE 7. Analysis of Simple Main Effects When Subjects of Varying Age Performed a Cognitive Task at Different Levels of Difficulty in a Rural Road Driving Environment

\begin{tabular}{lcccc}
\hline Source of Variation & $\boldsymbol{d f}$ & $\boldsymbol{M S}$ & $\boldsymbol{F}$ & $\boldsymbol{p}$ \\
\hline $\mathrm{A}($ Age level) at & & & & \\
$\mathrm{C}_{1}$ (Difficulty index level 1) & 3 & 2498459.7 & 71.3 & .00 \\
$\mathrm{C}_{2}$ (Difficulty index level 2) & 3 & 1875869.2 & 53.5 & .00 \\
$\mathrm{C}_{3}$ (Difficulty index level 3) & 3 & 1939519.3 & 55.3 & .00 \\
$\mathrm{C}$ (Difficulty index) at & & & & \\
$\mathrm{A}_{1}$ (Age level 1) & 2 & 1841647.2 & 159.6 & .00 \\
$\mathrm{~A}_{2}$ (Age level 2) & 2 & 1384829.1 & 120.0 & .00 \\
$\mathrm{~A}_{3}$ (Age level 3) & 2 & 1499219.1 & 129.9 & .00 \\
$\mathrm{~A}_{4}$ (Age level 4) & 2 & 1113823.6 & 96.5 & .00 \\
\hline
\end{tabular}

TABLE 8. Analysis of Simple Main Effects When Subjects of Age Level 1 Performed a Cognitive Task at Different Levels of Difficulty Under Different Levels of Equivalent Acceleration of Vibration in a Rural Road Driving Environment

\begin{tabular}{llccc}
\hline Source of Variation & $\boldsymbol{d f}$ & $\boldsymbol{M S}$ & $\boldsymbol{F}$ & $\boldsymbol{p}$ \\
\hline B (Equivalent acceleration of vibration level) at & & & & \\
C & & & & \\
(Difficulty index level 1) & 3 & 17090.70 & 5.95 & .00 \\
C $_{2}$ (Difficulty index level 2) & 3 & 53431.76 & 18.62 & .00 \\
C $_{3}$ (Difficulty index level 3) & 3 & 56314.40 & 19.62 & .00 \\
C (Difficulty index) at & & & & \\
B $_{1}$ (Equivalent acceleration of vibration level 1) & 2 & 76386.04 & 27.02 & .00 \\
B $_{2}$ (Equivalent acceleration of vibration level 2) & 2 & 91260.33 & 32.29 & .00 \\
B $_{3}$ (Equivalent acceleration of vibration level 3) & 2 & 155752.19 & 55.11 & .00 \\
B $_{4}$ (Equivalent acceleration of vibration level 4) & 2 & 156436.33 & 55.35 & .00 \\
\hline
\end{tabular}

TABLE 9. Analysis of Simple Main Effects When Subjects of Age Level 2 Performed a Cognitive Task at Different Levels of Difficulty Under Different Levels of Equivalent Acceleration of Vibration in a Rural Road Driving Environment

\begin{tabular}{|c|c|c|c|c|}
\hline Source of Variation & $d f$ & MS & $\boldsymbol{F}$ & $p$ \\
\hline \multicolumn{5}{|l|}{$\mathrm{B}$ (Equivalent acceleration of vibration level) at } \\
\hline $\mathrm{C}_{1}$ (Difficulty index level 1 ) & 3 & 40751.16 & 9.2 & .00 \\
\hline $\mathrm{C}_{2}$ (Difficulty index level 2) & 3 & 37924.83 & 8.56 & .00 \\
\hline $\mathrm{C}_{3}$ (Difficulty index level 3) & 3 & 60418.2 & 13.64 & .00 \\
\hline \multicolumn{5}{|l|}{ C (Difficulty index) at } \\
\hline $\mathrm{B}_{1}$ (Equivalent acceleration of vibration level 1) & 2 & 1460979.5 & 164.9 & .00 \\
\hline ghtB $_{2}$ (Equivalent acceleration of vibration level 2) & 2 & 1779646.5 & 200.9 & .00 \\
\hline $\mathrm{B}_{3}$ (Equivalent acceleration of vibration level 3) & 2 & 2110205.4 & 238.2 & .00 \\
\hline $\mathrm{B}_{4}$ (Equivalent acceleration of vibration level 4) & 2 & 2213961.2 & 249.9 & .00 \\
\hline
\end{tabular}


(Tables 8 and 9) performed the cognitive task. For age level 3 and 4 (Tables 10 and 11) the equivalent level of vibration acceleration at difficulty index level 2 and 3 and difficulty index at all four levels of vibration were statistically significant but it was found to have a nonsignificant effect at difficulty index level 1 .

Through regression analysis, the curves of best fit were obtained between reaction time and vibration level for both the difficulty index and levels of age and are presented in Figures 4 and 5. The governing equations for reaction time versus vibration level at different difficulty index levels were as follows:

$$
\begin{aligned}
& R T_{\mathrm{D} 1}=697.44+37.84 \mathrm{~V} \\
& R T_{\mathrm{D} 2}=786.32+58.55 \mathrm{~V}
\end{aligned}
$$

$$
R T_{\mathrm{D} 3}=891.47+61.95 \mathrm{~V}
$$

The reaction time models involving the level of vibration and different age groups were as follows:

$$
\begin{aligned}
& R T_{\mathrm{A} 1}=545.00+56.40 \mathrm{~V} \\
& R T_{\mathrm{A} 2}=677.50+58.90 \mathrm{~V} \\
& R T_{\mathrm{A} 3}=885.00+34.90 \mathrm{~V} \\
& R T_{\mathrm{A} 4}=876.50+36.79 \mathrm{~V}
\end{aligned}
$$

where $R T_{\mathrm{D} 1}, R T_{\mathrm{D} 2}$ and $R T_{\mathrm{D} 3}$ represent reaction time at difficulty index level 1,2 and 3 respectively, $R T_{\mathrm{A} 1}, R T_{\mathrm{A} 2}, R T_{\mathrm{A} 3}$ and $R T_{\mathrm{A} 4}$ show reaction time at age level $1,2,3$ and 4 respectively and $V$ is the value of equivalent acceleration of vibration.

TABLE 10. Analysis of Simple Main Effects When Subjects of Age Level 3 Performed a Cognitive Task at Different Levels of Difficulty Under Different Levels of Equivalent Acceleration of Vibration in a Rural Road Driving Environment

\begin{tabular}{llrrr}
\hline Source of Variation & $\boldsymbol{d f}$ & $\boldsymbol{M S}$ & $\boldsymbol{F}$ & $\boldsymbol{p}$ \\
\hline $\mathrm{B}$ (Equivalent acceleration of vibration level) at & & & & \\
$\mathrm{C}_{1}$ (Difficulty index level 1) & 3 & 6865.5 & 2.75 & .07 \\
$\mathrm{C}_{2}$ (Difficulty index level 2) & 3 & 35947.0 & 14.40 & .00 \\
$\mathrm{C}_{3}$ (Difficulty index level 3) & 3 & 9332.4 & 3.74 & .03 \\
$\mathrm{C}$ (Difficulty index) at & & & & \\
$\mathrm{B}_{1}$ (Equivalent acceleration of vibration level 1) & 2 & 99467.4 & 25.80 & .00 \\
$\mathrm{~B}_{2}$ (Equivalent acceleration of vibration level 2) & 2 & 84577.7 & 21.96 & .00 \\
$\mathrm{~B}_{3}$ (Equivalent acceleration of vibration level 3) & 2 & 106714.9 & 27.70 & .00 \\
$\mathrm{~B}_{4}$ (Equivalent acceleration of vibration level 4) & 2 & 96590.3 & 25.08 & .00 \\
\hline
\end{tabular}

TABLE 11. Analysis of Simple Main Effects When Subjects of Age Level 4 Performed a Cognitive Task at Different Levels of Difficulty Under Different Levels of Equivalent Acceleration of Vibration in a Rural Road Driving Environment

\begin{tabular}{lrrrr}
\hline Source of Variation & $\boldsymbol{d f}$ & $\boldsymbol{M S}$ & $\boldsymbol{F}$ & $\boldsymbol{p}$ \\
\hline $\mathrm{B}$ (Equivalent acceleration of vibration level) at & & & & \\
$\mathrm{C}_{1}$ (Difficulty index level 1) & 3 & 5544.61 & 1.67 & .21 \\
$\mathrm{C}_{2}$ (Difficulty index level 2) & 3 & 15953.42 & 4.81 & .01 \\
$\mathrm{C}_{3}$ (Difficulty index level 3) & 3 & 44994.20 & 13.57 & .00 \\
$\mathrm{C}$ (Difficulty index) at & & & & \\
$\mathrm{B}_{1}$ (Equivalent acceleration of vibration level 1) & 2 & 47700.0 & 39.20 & .00 \\
$\mathrm{~B}_{2}$ (Equivalent acceleration of vibration level 2) & 2 & 38403.5 & 31.50 & .00 \\
$\mathrm{~B}_{3}$ (Equivalent acceleration of vibration level 3) & 2 & 90023.2 & 74.00 & .00 \\
$\mathrm{~B}_{4}$ (Equivalent acceleration of vibration level 4) & 2 & 117295.8 & 96.42 & .00 \\
\hline
\end{tabular}




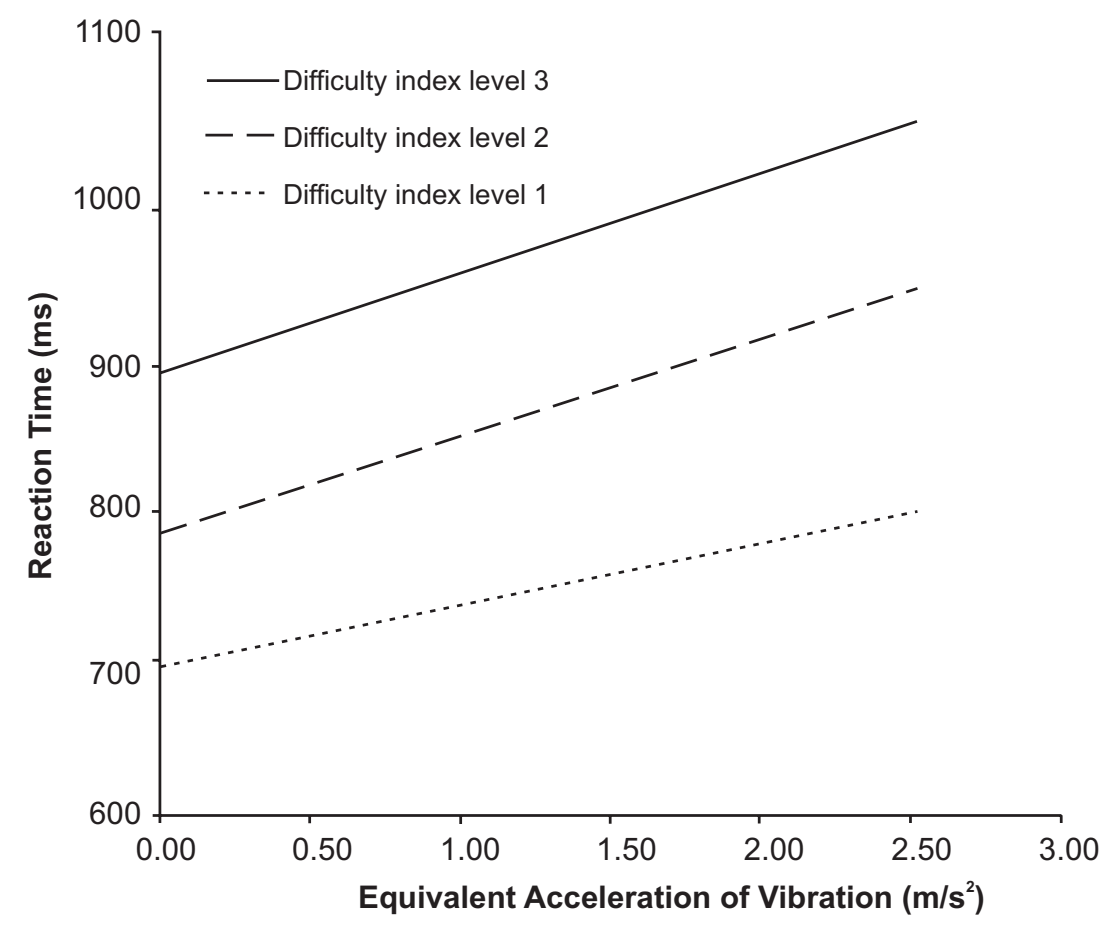

Figure 4. Relationship between reaction time and equivalent acceleration of vibration for different levels of difficulty in a rural road driving environment.

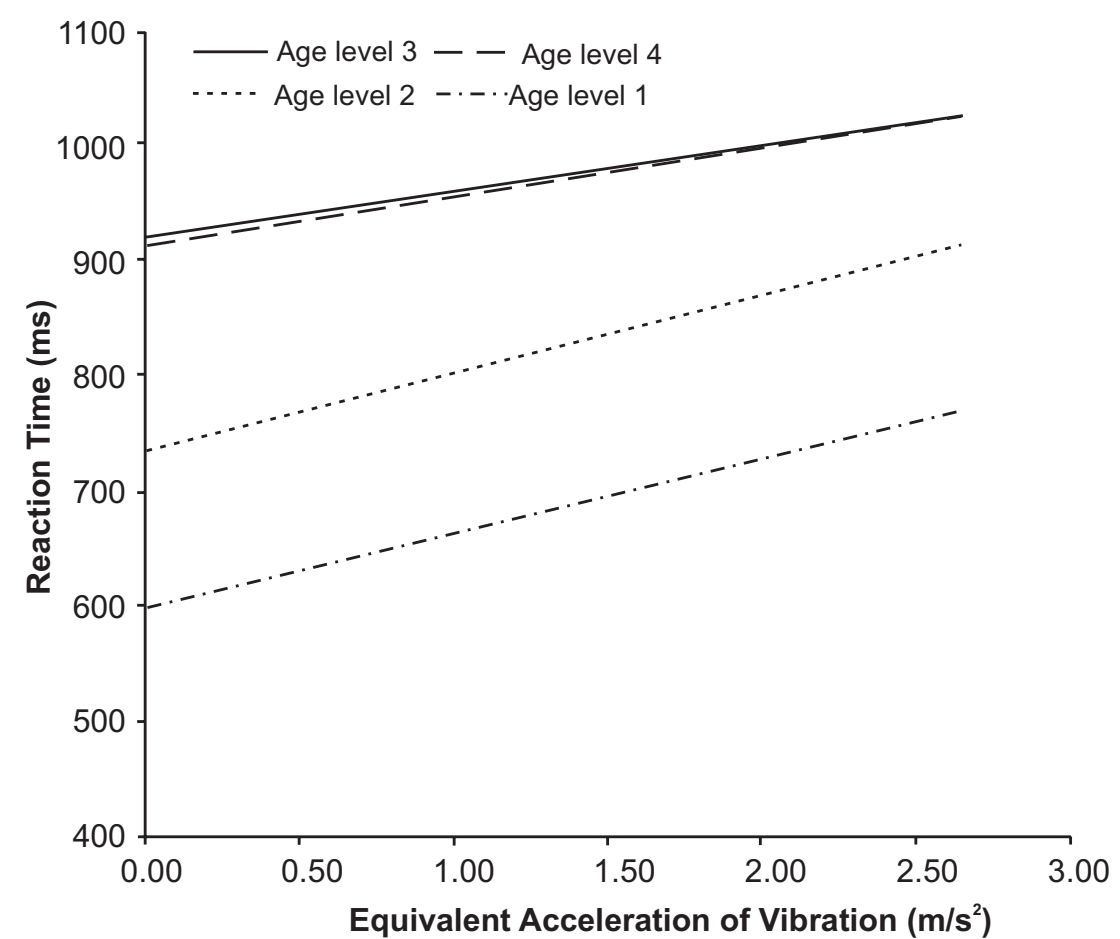

Figure 5. Relationship between reaction time and equivalent acceleration of vibration for varying levels of age in a rural road driving environment.

\subsection{Experiment 3}

This study was undertaken to explore human performance in a highway environment of driving.
Results of the analysis of variance carried out (Table 12) showed that the main effect of age was statistically non-significant implying that cognitive 
performance was independent of the age of the subjects exposed to varying levels of vehicular vibration in the environment of highway driving. The main effect of the equivalent level of vibration acceleration and the difficulty index were both found to be statistically significant. The interaction effects of age with the difficulty index, age with the level of equivalent acceleration of vibration, and the level of equivalent acceleration of vibration with the difficulty index were all found to be statistically significant. The second order interaction age $\times$ level of vibration $\times$ difficulty index was also found to be statistically significant.
The simple main effects analysis carried out for the subjects of varying age performing the task at varying levels of vehicular vibration (Table 13) revealed that both the age level at all the four levels of vibration and the levels of equivalent acceleration of vibration at all levels of age undertaken in the study were statistically significant.

The analysis of the simple main effects for subjects of varying age performing a task at three levels of difficulty (Table 14) found that the age level at a simple task (difficulty index level 1) as well as the choice reaction type of task (difficulty

TABLE 12. ANOVA Results When Operators Performed a Cognitive Task in a Highway Driving Environment

\begin{tabular}{lcccc}
\hline Source of Variation & $\boldsymbol{d f}$ & $\boldsymbol{M S}$ & $\boldsymbol{F}$ & $\boldsymbol{p}$ \\
\hline Between subjects & 27 & 35345.51 & & .64 \\
A (Age) & 3 & 2784.34 & 0.56 & \\
Subjects within groups (Error 1) & 24 & 4959.4 & & .00 \\
Within subjects & 308 & 12767.85 & & .00 \\
B (Equivalent acceleration of vibration level) & 3 & 185470.00 & 83.37 & 23.30 \\
A $\times$ B & 9 & 5762.50 & & .00 \\
B $\times$ subjects within groups (Error 2) & 72 & 2224.54 & & .00 \\
C (Difficulty index) & 2 & 1238642.65 & 899.80 & 29.09 \\
A $\times$ C & 6 & 40041.26 & & .01 \\
C $\times$ subjects within groups (Error 3) & 48 & 1376.53 & 6.85 & .01 \\
B $\times$ C & 6 & 9712.00 & 4.62 & .01 \\
A $\times$ B $\times$ C & 18 & 6557.00 & & .00 \\
B $\times$ C $\times$ subjects within groups & 144 & 1417.70 & & \\
\hline
\end{tabular}

TABLE 13. Analysis of Simple Main Effects When Subjects of Varying Age Performed a Cognitive Task Under Different Levels of Equivalent Acceleration of Vibration in a Highway Driving Environment

\begin{tabular}{llccc}
\hline Source of Variation & $\boldsymbol{d f}$ & $\boldsymbol{M S}$ & $\boldsymbol{F}$ & $\boldsymbol{p}$ \\
\hline $\mathrm{A}$ (Age level) at & & & & \\
$\mathrm{B}_{1}$ (Equivalent acceleration of vibration level 1) & 3 & 251675.1 & 16.5 & .00 \\
$\mathrm{~B}_{2}$ (Equivalent acceleration of vibration level 2) & 3 & 252333.1 & 16.6 & .00 \\
$\mathrm{~B}_{3}$ (Equivalent acceleration of vibration level 3) & 3 & 144217.8 & 9.4 & .00 \\
$\mathrm{~B}_{4}$ (Equivalent acceleration of vibration level 4) & 3 & 238940.1 & 15.6 & .00 \\
$\mathrm{~B}$ (Equivalent acceleration of vibration level) at & & & & .00 \\
$\mathrm{~A}_{1}$ (Age level 1) & 3 & 108531.8 & 24.2 & .00 \\
$\mathrm{~A}_{2}$ (Age level 2) & 3 & 137227.3 & 30.6 & .00 \\
$\mathrm{~A}_{3}$ (Age level 3) & 3 & 286958.4 & 64.0 & .00 \\
$\mathrm{~A}_{4}$ (Age level 4) & 3 & 75555.8 & 16.8 & .00 \\
\hline
\end{tabular}


TABLE 14. Analysis of Simple Main Effects When Subjects of Varying Age Performed a Cognitive Task at Different Levels of Difficulty in a Highway Driving Environment

\begin{tabular}{llccc}
\hline Source of Variation & $\boldsymbol{d f}$ & $\boldsymbol{M S}$ & $\boldsymbol{F}$ & $\boldsymbol{p}$ \\
\hline $\mathrm{A}$ (Age level)at & & & & \\
$\mathrm{C}_{1}$ (Difficulty index level 1) & 3 & 852196.6 & 41.8 & .00 \\
$\mathrm{C}_{2}$ (Difficulty index level 2) & 3 & 323804.2 & 15.9 & .00 \\
$\mathrm{C}_{3}$ (Difficulty index level 3) & 3 & 258066.9 & 12.7 & .00 \\
$\mathrm{C}($ Difficulty index) at & & & & \\
$\mathrm{A}_{1}$ (Age level 1) & 2 & 2925227.5 & 645.6 & .00 \\
$\mathrm{~A}_{2}$ (Age level 2) & 2 & 817135.1 & 180.3 & .00 \\
$\mathrm{~A}_{3}$ (Age level 3) & 2 & 786502.7 & 173.6 & .00 \\
$\mathrm{~A}_{4}$ (Age level 4) & 2 & 906200.1 & 200.0 & .00 \\
\hline
\end{tabular}

TABLE 15. Analysis of Simple Main Effects When Subjects Performed a Cognitive Task at Varying Levels of Difficulty Under Different Levels of Equivalent Acceleration of Vibration in a Highway Driving Environment

\begin{tabular}{llccc}
\hline Source of Variation & $\boldsymbol{d f}$ & $\boldsymbol{M S}$ & $\boldsymbol{F}$ & $\boldsymbol{p}$ \\
\hline $\mathrm{B}$ (Equivalent acceleration of vibration level) at & & & & \\
$\mathrm{C}_{1}$ (Difficulty index level 1) & 3 & 206951.6 & 34.6 & .00 \\
$\mathrm{C}_{2}$ (Difficulty index level 2) & 3 & 323975.1 & 54.2 & .00 \\
$\mathrm{C}_{3}$ (Difficulty index level 3) & 3 & 288650.7 & 48.3 & .00 \\
$\mathrm{C}$ (Difficulty index) at & & & & \\
$\mathrm{B}_{1}$ (Equivalent acceleration of vibration level 1) & 2 & 942270.3 & 219.0 & .00 \\
$\mathrm{~B}_{2}$ (Equivalent acceleration of vibration level 2) & 2 & 1636178.1 & 361.1 & .00 \\
$\mathrm{~B}_{3}$ (Equivalent acceleration of vibration level 3) & 2 & 868766.1 & 191.7 & .00 \\
$\mathrm{~B}_{4}$ (Equivalent acceleration of vibration level 4) & 2 & 1573901.3 & 347.4 & .00 \\
\hline
\end{tabular}

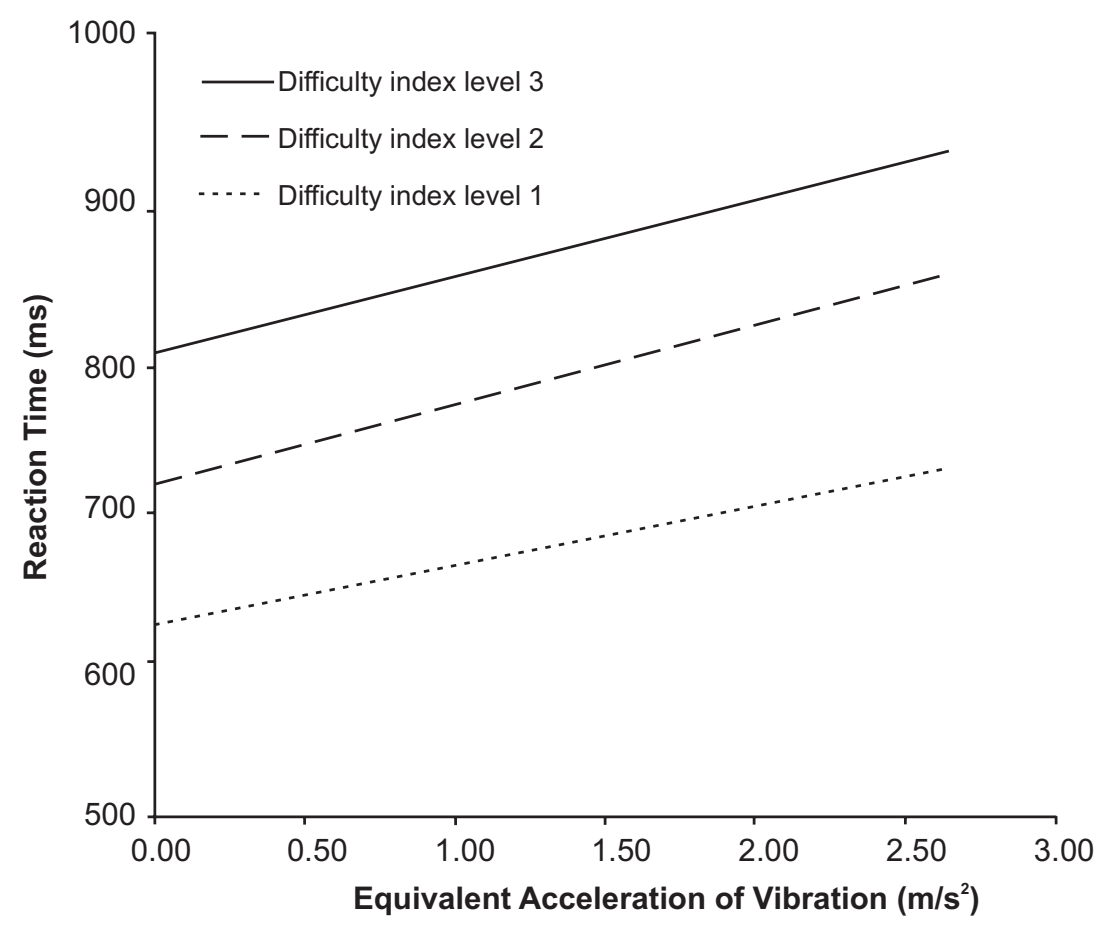

Figure 6. Relationship between reaction time and equivalent acceleration of vibration for different levels of difficulty in a highway driving environment. 
index level 2 and 3) and the difficulty index level at varying levels of age were statistically significant. The results of the simple main effects analysis (Table 15) for subjects performing a task at varying levels of difficulty under different levels of vibration indicated that vehicular vibration at all the three levels of difficulty and the difficulty index at four levels of vehicular vibration were statistically significant.

The governing equations for reaction time versus vibration level at different difficulty indices were obtained as follows (Figure 6).

$$
\begin{aligned}
& R T_{\mathrm{D} 1}=619.64+34.09 \mathrm{~V} \\
& R T_{\mathrm{D} 2}=728.70+45.94 \mathrm{~V} \\
& R T_{\mathrm{D} 3}=817.03+42.64 \mathrm{~V}
\end{aligned}
$$

where $R T_{\mathrm{D} 1}, R T_{\mathrm{D} 2}$ and $R T_{\mathrm{D} 3}$ represent reaction time at difficulty index level 1,2 and 3 respectively and $V$ is the value of equivalent acceleration of vibration.

\section{DISCUSSION}

The hypotheses posed earlier were tested and found to contradict for the level of equivalent acceleration of vibration and the difficulty index. They were also contradicted for age in the city street and the rural road environment of driving but accepted for the highway driving environment. Results of the aforementioned studies indicated that in a city street and rural environment of driving age-related effects in cognitive tasks were statistically significant while in a highway environment of driving age was found to be statistically non-significant. The reason might be traced in terms of the fact that highway traffic is more organized compared to the relative chaos in city streets and also highways are better quality. Because of these two conditions people are relieved of mental tensions as regards to traffic and other environmental stressors, while in city streets and rural roads, drivers have to be mentally alert all the time to avoid any mishaps. According to Kumashiro [9], biological and physiological functions in humans generally reach their peak and then tend to decline The review of previous research revealed that almost no study has been conducted to determine cognitive performance in a driving environment. However, other related research $[3,4,6,10,11]$ has shown significant effect of age on human performance. The equivalent acceleration of vibration level was found to have a significant effect on human performance in the three environments of driving considered in this study. These results are in conformity with Shoenberger [2] and Zepler et al. [12] who showed degradation in performance due to vibration. The results of the present work also indicated that the difficulty index level of a cognitive task was highly significant and needs to be given proper and due attention. Fell [13] showed that $45.7 \%$ of accidents occurred due to definite involvement in recognition of errors. The results of another study [14] found that accidents happened because of drivers' failure in adequate decision making. Results of the present study also showed that the level of equivalent acceleration of vibration and the difficulty index had a statistically significant effect on human cognitive performance. These findings are in line with previous research which showed degradation in performance under the impact of vibration.

\section{CONCLUSION}

Based on section 4, the following conclusion were drawn:

1. Organismic variable age had a significant negative effect on task performance in city street and rural road driving but had no significant effect on task performance in highway driving.

2. Vehicular vibration had a significant negative effect on performance under all driving conditions, i.e., in city street, rural road and highway environments of driving.

3. The cognitive task difficulty index had a significant negative effect on task performance. 


\section{REFERENCES}

1. Fairley TE. Predicting the discomfort caused by tractor vibration. Ergonomics 1995;38(10):2091-106.

2. Shoenberger RW. An investigation of human information processing during whole body vibration. Aerosp Med 1974;38: 1264-9.

3. Welford AT. Signal, noise, performance, and age. Hum Factors 1981;23(1):97-109.

4. Czaja S. Microcomputers and the elderly. In: Helander M, editor. Handbook of human-computer interaction, Amsterdam, The Netherlands: North Holland; 1988.

5. Yamamoto S, Yoshioka M, Noro K. A study of the adaptability of operators aging characteristics to VDU works. Ergonomics 1982;25:557-62.

6. Salthouse TA. Adult cognition: an experimental psychology on human aging. New York, NY, USA, Springer-Verlag; 1982.

7. Kausler DH. Experimental psychology and human aging. New York, NY, USA: Wiley; 1982.
8. International Organization for Standardization (ISO). Mechanical vibration and shock-evaluation of human exposure to whole-body vibration-part 1: general requirements (Standard No. ISO 2631-1:1997). Geneva, Switzerland: ISO; 1997.

9. Kumashiro M. The effect of stress on middle aged and elderly worker: Two case studies. Ergonomics International 1985;L5/3:946-8.

10. Van Zelst RH. The effects of age and experience upon accident rate. J Appl Psychol 1954;38: 313-7.

11. Oborne DJ. Ergonomics at work. New York, NY, USA: Wiley; 1986.

12. Zepler EE, Sullivan BM, Rice CG, Griffin MJ, Oldman M, Dickinson PJ, Shepherd KP, Ludlow JE, Large JB. Human response to transportation noise and vibration. $\mathrm{J}$ Sound Vib 1973;28(3):375-401.

13. Fell JC. A motor vehicle accident casual system: the human element. Hum Factors 1976;18(1):85-94.

14. Malatterre G. Error analysis and indepth accident studies. Ergonomics 1990;33: 1403-21. 